\title{
Increased Left Atrial Volume and Its Relationship to Vitamin D in Primary Care
}

Erica de Abreu Macedo, ${ }^{\circledR}$ Maria Luiza Garcia Rosa, ${ }^{\circledR}$ Antônio José Lagoeiro Jorge, ${ }^{\circledR}$ Adson Renato Leite, ${ }^{\circledR}$ Leivys Henrique Silva Santos, Juliana Salge Vieira

Universidade Federal Fluminense, Niterói, RJ - Brazil

\section{Abstract}

Background: The study is based on the fact that left atrial (LA) volume measurement is a marker of the presence of diastolic dysfunction and that Vitamin D deficiency may be associated with ventricular remodeling, worsening of left ventricular (LV) diastolic and systolic function, and activation of the renin-angiotensinaldosterone system.

Objective: To evaluate whether LAV changes are related to vitamin D deficiency.

Method: A cross-sectional, population-based, unicentric study in which 640 patients over 45 years of age enrolled in the Niterói's Médico de Família program, RJ, were evaluated. Patients were submitted to tissue Doppler echocardiography to evaluate the parameters of diastolic and systolic function and vitamin $\mathrm{D}$ dosage. The presence or absence of hypovitaminosis D associated with structural and functional cardiac changes was compared between each group. A p $<0.05$ value was considered as an indicator of statistical significance.

Results: Of the 640 individuals analyzed, hypovitaminosis D was confirmed in $39.2 \%$ of the patients, of whom $34.8 \%$ had diastolic dysfunction. The most relevant echocardiographic parameters that were statistically significant were non-indexed AEDs and LAV, E' / A' and E wave deceleration time, which were associated with the presence of hypovitaminosis $\mathrm{D}(\mathrm{P}<0.01)$.

Conclusion: The study of the association of hypovitaminosis D and the appearance of structural and functional cardiac abnormalities may contribute to the discussion of the adoption of one more criterion to select individuals at risk of developing clinical cardiac insufficiency in primary care since, with the use of echocardiography, the subclinical condition of cardiac involvement, with prognostic and treatment implications for the referred patients with hypovitaminosis D, can be identified early. (Int J Cardiovasc Sci. 2019;32(5):508-516)

Keywords: Heart Atria; Atrial Function; Cholecalciferol; Primary Health Care; Heart Failure; Echocardiography.

\section{Introduction}

Left atrial volume indexed to body surface area (LAV/ BSA) provides accurate assessment of LA size, serving as a reference and an excellent marker of the diastolic dysfunction chronicity, cardiovascular risk, left ventricular (LV) filling pressure and, above all, of the morphophysiologic expression of LV diastolic dysfunction. ${ }^{1-2}$

LAV has been used to grade the progressive impairment of LV diastolic function (Figure 1). ${ }^{3}$ It is also a well-validated echocardiographic parameter for differential diagnosis of heart failure with a normal ejection fraction (HFNEF). ${ }^{4}$

Vitamin D has been associated with cardiovascular disease, especially regarding the pathophysiology of heart failure (HF). ${ }^{5}$

Studies associating hypovitaminosis D with parameters of morphofunctional changes are still controversial in the literature, both in relation to the circulating levels and the type of supplementation. ${ }^{6}$ 
In a recent review of the literature, Lagoeiro et al., ${ }^{7}$ demonstrated that the efficacy of Vitamin D supplementation is not clear yet. It is unknown whether the unfavorable results are a consequence of inadequate supplementation dosage or the inability of the vitamin in exerting favorable metabolic effects on already established diseases. ${ }^{7}$ On the other hand, Vitamin D deficiency has been associated with the worsening of quality of life and a decrease in functional performance, due to abnormal LV systolic and diastolic functions and vascular system, and thus may contribute to the genesis or progression of HF. .-8-10 $^{-10}$

Vitamin D is associated with the worsening of diastolic function and activation of the renin-angiotensinaldosterone system (RAAS). ${ }^{8-9}$

The study is based on the fact that left atrial volume (LAV) measurement is a marker of the presence of diastolic dysfunction and that Vitamin D deficiency may be associated with ventricular remodeling, worsened LV systolic and diastolic function and RAAS activation.

The objective of this study is to evaluate whether LAV changes are related to Vitamin D deficiency and to verify whether there is a relationship with ventricular remodeling and other parameters of systolic function (S') and diastolic function (LV relaxation and filling pressure).

\section{Methodology}

Cross-sectional, population-based, unicentric study, and part of the Digitalis Study, ${ }^{11}$ involving 640 randomly selected individuals, aged over 45 years, enrolled in the Niterói's Médico de Família program. Vitamin D dosage and cardiac structural and functional abnormalities, assessed using transthoracic echocardiography, were included among the criteria for classification of hypovitaminosis $\mathrm{D}$. The presence or absence of hypovitaminosis D, associated with structural and functional abnormalities, was compared between each group.

The units and individuals at each unit were selected through computer-generated random sequence, where the weight of each unit was proportional to the number of individuals assisted.

All individuals selected in the study underwent a single-day evaluation, which consisted of the following procedures: blood collection (including a Vitamin D test), urine collection, consultation and clinical examination, nutritional assessment, measurement of blood pressure, heart rate, body weight, height and abdominal-waist circumference, filling out of a questionnaire adapted for this study, 12-lead electrocardiogram (ECG) and tissue Doppler echocardiogram (TDE).

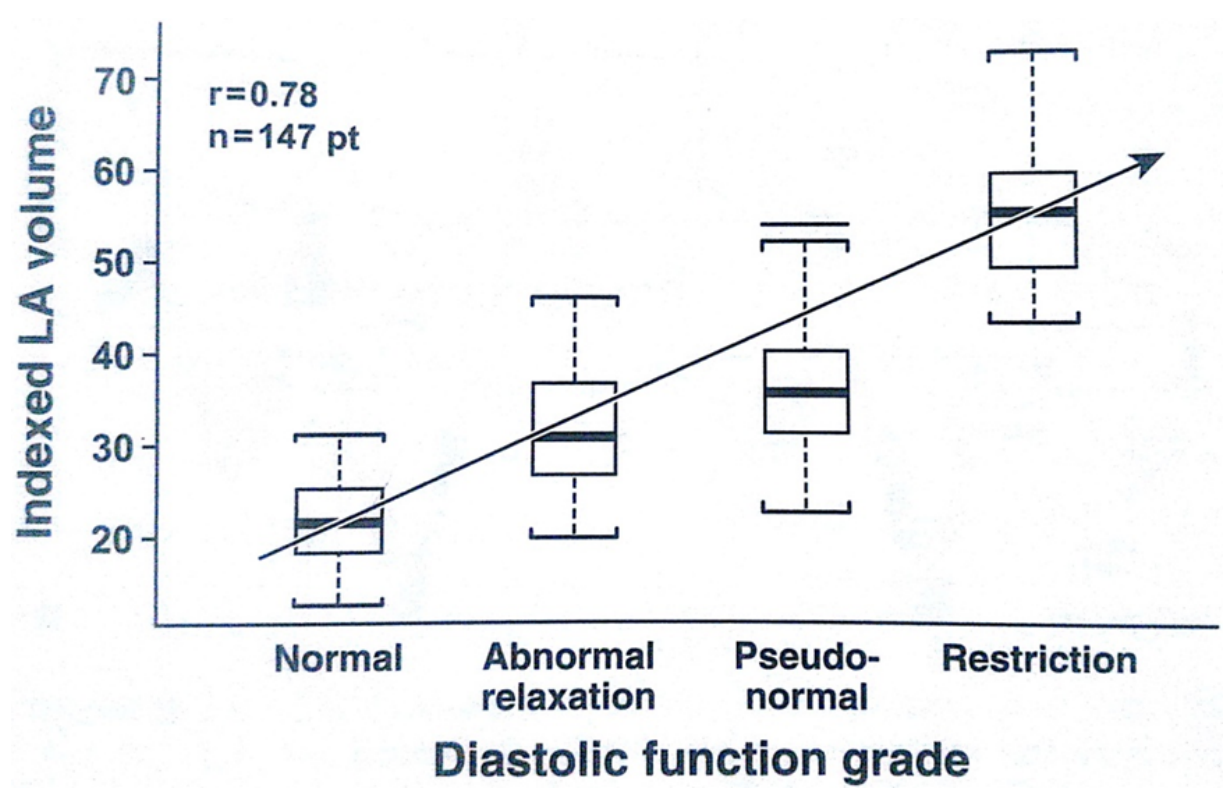

Figure 1 - Volume index versus diastolic dysfunction. The volume index increases as the diastolic function worsens. ${ }^{3}$ 
Inclusion criteria were: age equal to or over 45 years and signed Informed Consent Form. Individuals with clinical heart failure (using the major and minor clinical criteria - Table 1), those impeded to carry out the necessary procedures for the evaluation and patients with clinical conditions that would enable them to attend the health unit to undergo the exams were excluded.

Two devices were used to perform the echocardiogram and tissue Doppler imaging: Cypress 20 Acuson (Siemens, Mountain View, EUA) and AU-3 Partner (Esaote, Florence, Italy). The examinations were performed by two experienced echocardiographists without previous knowledge of the results of other clinical and laboratory tests. Three repeated measurements were obtained from each parameter and the resulting mean was used in the study. The tests were performed according to the recommendations for the quantification of chambers of the American Society of Echocardiography (ASE) and European Association of Echocardiography (EAE). ${ }^{12}$

Systolic function was assessed by measurement of left ventricular ejection fraction (LVEF) using Simpson's method and the longitudinal axis stretching $\left(\mathrm{S}^{\prime}\right)$. Diastolic function parameters were obtained using tissue Doppler (TDE).

Diastolic diameter, $\mathrm{cm}, 3.9-5.3$ (women) and 4.2-5.9 (men), indexed to $2.4-3.2 \mathrm{~cm} / \mathrm{cm}^{2}$ and $2.2-3.1 \mathrm{~cm} / \mathrm{cm}^{2}$, and systolic diameter of $2.1-4.0 \mathrm{~cm}$, indexed to $1.4-2.1 \mathrm{~cm} / \mathrm{cm}^{2} .{ }^{13}$

Left atrial volume (LAV) was obtained using Simpson's method of disks, in which the left atrial

Table 1 - Clinical criteria for the diagnosis of heart failure - modified Framingham

\begin{tabular}{lc}
\hline Major criteria & Minor criteria \\
\hline Paroxysmal nocturnal dyspnea & Edema \\
Orthopnea & Nocturnal cough \\
$\begin{array}{l}\text { Abnormal jugular venous } \\
\text { distension }\end{array}$ & Dyspnea on exertion \\
Lung crackles & Pleural effusion \\
Cardiomegaly & Tachycardia (> 120 bpm) \\
$\begin{array}{l}\text { Pulmonary edema } \\
\text { Hepatojugular reflux }\end{array}$ & Weight loss $\geq 4.5$ kg in 5 days \\
\hline $\begin{array}{l}\text { Heart failure is considered to be present if two major criteria or one } \\
\text { major and two minor criteria are present. }\end{array}$
\end{tabular}

endocardial border is traced in the apical 4- and apical 2-chamber views, as shown by Figure 2. The areas are obtained in the apical positions, excluding the left atrial appendage and the confluence of the pulmonary veins; the perpendicular length is measured between the MV annulus plane and the upper portion of the LA, and reference value is $28 \mathrm{~mL} / \mathrm{m}^{2}$ for both sexes. ${ }^{14}$ In the study, increase in LAV-I from $28 \mathrm{~mL} / \mathrm{m}^{2}$ was considered.

Echodopplercardiography and tissue Doppler (TDE) were performed by an experienced echocardiographer, using pre-established patterns and without prior knowledge of the results of other tests. All exams were reviewed by another echocardiographer, who would emit the reports independently of the first examiner.

Diastolic dysfunction has been defined as the presence of abnormalities in ventricular relaxation, assessed by the measurement of the septal $\mathrm{E}^{\prime}$ wave less than $8 \mathrm{~cm} / \mathrm{s}$ and / or the presence of increased filling pressures of the left ventricle, using E/ E' greater than or equal to 15 and the increase in indexed left atrial volume greater than or equal to $28 \mathrm{~mL} / \mathrm{m}^{2} .^{13}$

TDE measurements for the mitral annulus velocity in early diastole in the septal wall ( $\mathrm{E}^{\prime}$ wave) reflects LV relaxation and, in combination with the measurement of transmitral flow in early diastole (E wave), E/E' ratio, can be used to predict LV filling pressures. ${ }^{15}$

Diastolic function parameters obtained with TDE, in the long-axis and four-chamber view, were performed in the septal and lateral regions of the mitral annulus, and early (E') and late (A') diastolic mitral annular velocities were obtained from a long-axis view.

Transmitral early diastolic flow velocity (E), deceleration time (DT) and transmitral end diastolic flow velocity (A) were assessed by conventional echoDoppler cardiography.

Measurements of left ventricular (LV) and LA dimensions were made by M-mode from parasternal view.

Diastolic dysfunction (DD) grades were established according to the following criteria:

Grade I DD (mild) - presence of $\mathrm{E}^{\prime}<8$ and / or LAV-I $\geq 28 \mathrm{~mL} / \mathrm{m}^{2}$ with $\mathrm{E} / \mathrm{E}^{\prime}$ ratio $<8$.

Grade II DD (moderate) - presence of $\mathrm{E}^{\prime}<8$ and / or $\mathrm{LAV}-\mathrm{I} \geq 28 \mathrm{~mL} / \mathrm{m}^{2}$ with $\mathrm{E} / \mathrm{E}^{\prime}$ ratio $\geq 8$ and $<15$.

Grade III DD (severe) - presence of $E / E^{\prime}$ ratio $\geq 15$.

The determination of Vitamin D levels was performed using the LIAISON ${ }^{\circledR} 25 \mathrm{OH}$ Vitamin D Assay and a direct 

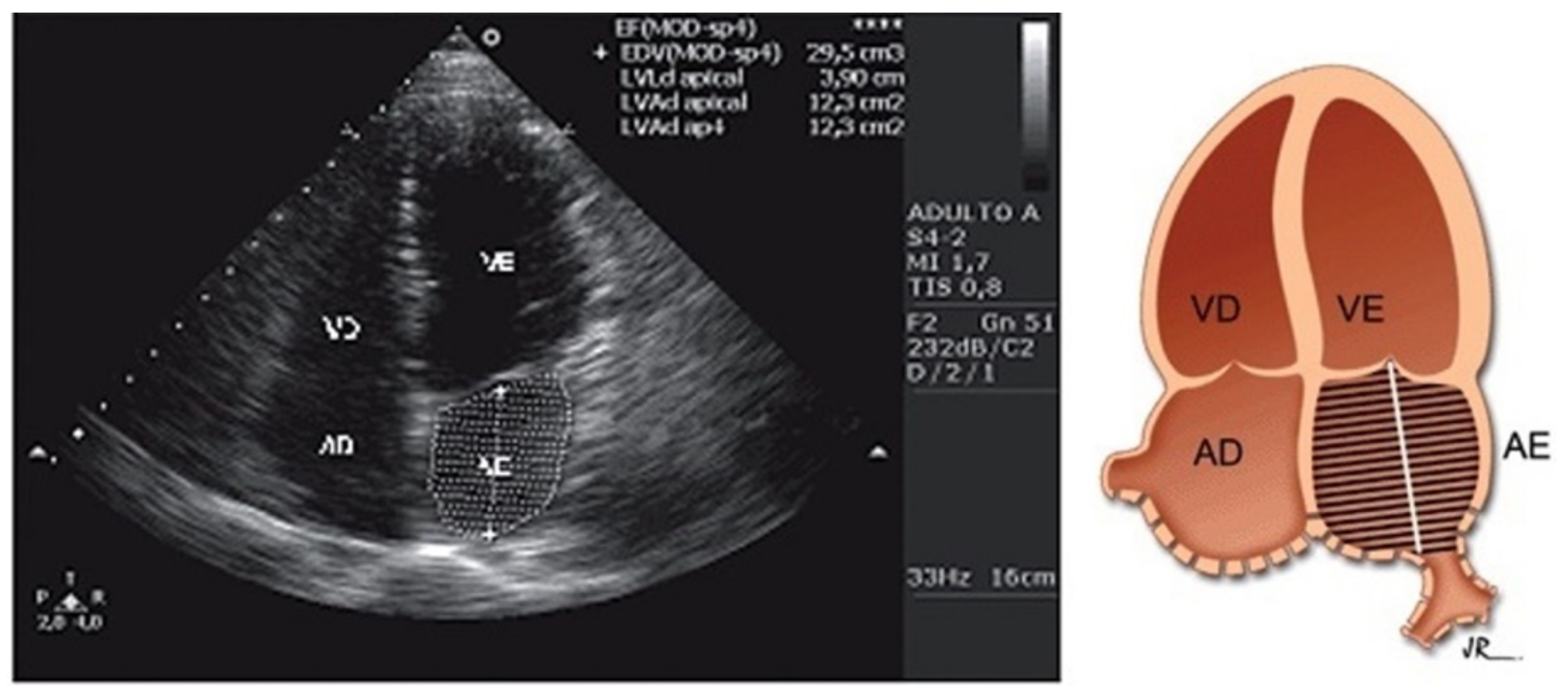

Figure 2 - Schematic representation of LAVi measured by biplane Simpson's method, at end-systole, in 4- and 2-chamber views. ${ }^{14}$

test based on the principle of chemiluminescence. Blood or anticoagulated blood was used, with values estimated in $\mathrm{ng} / \mathrm{ml} .^{15}$

Interest exposure definition: Vitamin D deficiency may worsen the diastolic function and contribute to hypertrophy of myofibrils and death of cardiomyocytes, resulting in arrhythmias and altered endothelial function, since cardiomyocytes possess a vitamin $\mathrm{D}$ receptor and a calcitriol-dependent $\mathrm{Ca}^{2+}$ binding protein, which can modulate contraction of cardiomyocytes. When at decreased levels, they might contribute to contractile changes and constitute a pathogenic factor in the onset of the cardiomyopathy. ${ }^{5}$

It is estimated that 1 billion people worldwide exhibit moderate or severe deficiency of Vitamin D.8,9,16 This is mainly related with: insufficient ingestion, inadequate sun exposure, liver disease and renal failure.

Table 2 - Criteria of vitamin D deficiency ${ }^{15}$

\begin{tabular}{ll}
\hline $25(\mathrm{OH}) \mathrm{D}(\mathrm{ng} / \mathrm{ml})$ & Status \\
\hline$>30$ & Sufficiency \\
$<20$ & Deficiency \\
\hline
\end{tabular}

\section{Statistical Analysis}

The Statistical Package for the Social Sciences, version 17.0 (SPSS Inc., Chicago, IL, USA) was used for all computations. All data were presented using summarized descriptive tables. Data were expressed as mean (SD) for continuous variables and frequency for categorical variables. Comparisons between groups were performed using Pearson's chi-square for categorical variables and Student's t-test for continuous variables. A value of $\mathrm{P}<0.05$ was used as an indicator of statistical significance.

\section{Results}

Hypovitaminosis D was confirmed in $39.2 \%$ of patients, of whom $34.8 \%$ presented with diastolic dysfunction. We observed that it could be established even in later phases of diastole, that is, in LV compliance, which may cause hemodynamic repercussion, due to increased filling pressure, and the major parameters used to clarify this condition of severity.

Table 3 shows the characteristics of the individuals analyzed according to the presence of hypovitaminosis $D$. There was significant statistical difference between the mean values of SBP (+), DBP (+) and BMI, and between 
Table 3 - Frequency risk factor distribution or mean (SD) according with the presence of hypovitaminosis D

\begin{tabular}{c} 
Hypovitaminosis D \\
\cline { 2 - 3 } Yes No \\
\hline
\end{tabular}

Sex

\begin{tabular}{|c|c|c|}
\hline Men & $80(37.0)$ & $136(63.0)$ \\
\hline Women & $143(41.0)$ & $210(59.0)$ \\
\hline Age & $57.79 \pm 0.55$ & $58.82 \pm 0.55$ \\
\hline $\mathrm{SBP}(\mathrm{mmHg}) \phi$ & $139,7 \pm 1.44$ & $134,41 \pm 1.23^{* * *}$ \\
\hline DBP $(\mathrm{mmHg}) ¥$ & $85,04 \pm 0.83$ & $80,58 \pm 0.62$ \\
\hline \multicolumn{3}{|l|}{ Hypertension\# } \\
\hline Yes & 199 (49.9) & $202(50.01)$ \\
\hline No & $24(14.3)$ & $144(85.7)$ \\
\hline \multicolumn{3}{|l|}{ Diabetes $£$} \\
\hline Yes & $62(44.0)$ & $78(56.0)$ \\
\hline No & $161(38.0)$ & $267(62.0)$ \\
\hline \multicolumn{3}{|l|}{ Obesity } \\
\hline $\mathrm{BMI} \$ \geq 30$ & $103(61.0)$ & $66(39.0)^{* \star *}$ \\
\hline $\mathrm{BMI}<30$ & $118(30.0)$ & $280(70.0)$ \\
\hline BMI & 29.950 .37 & $26,70.27^{* * *}$ \\
\hline LDL (mg/dL) & $139,892.68$ & $134,062.19^{*}$ \\
\hline HDL (mg/dL) & $54,391.10$ & $54,630.87$ \\
\hline Triglycerides & $181,9535.51$ & $139,186.64$ \\
\hline \multicolumn{3}{|l|}{ Infarction€ } \\
\hline Yes & $9(47.0)$ & $10(53.0)$ \\
\hline No & $214(39.0)$ & $336(61.0)$ \\
\hline \multicolumn{3}{|l|}{ Stroke€ } \\
\hline Yes & $11(58.0)$ & $8(42.0)$ \\
\hline No & $212(39.0)$ & $338(61.0)$ \\
\hline \multicolumn{3}{|c|}{$\begin{array}{l}\phi: \text { systolic blood pressure; } ¥ \text { : diastolic blood pressure; } \# \text { : previous } \\
\text { diagnosis, or use of medication or blood pressure } \geq 140 / 90 \mathrm{mmHg} ; € \text { : } \\
\text { previous diagnosis, or use of medication or fasting glycemia } \geq 126 \mathrm{mg} / \\
d L ; \$: \text { body mass index; } €: \text { patient report; }{ }^{* P} \text { value of chi-square or } t \\
\text { tests } \geq 0.05 \text { and }<0.1 ; * * * P \text { value of chi-square or } t \text { tests }<0.01 \text {. }\end{array}$} \\
\hline
\end{tabular}

the proportions of obesity. The differences in means of LDL-Cholesterol values and in proportions of stroke reached a statistical significance of $>0.1$.
Table 4 - Difference in means of echocardiographic parameters as markers of major diastolic dysfunction according with the presence of hypovitaminosis D

$\begin{array}{llll}\begin{array}{l}\text { Parameters } \\ \text { measured } \\ \text { by echo- } \\ \text { Doppler }\end{array} & & & \\ & & & \\ \text { Hypovitaminosis D }\end{array}$

${ }^{*} P$ value of $t$ tests $\geq 0.05$ and $<0.1 ;{ }^{* *} P$ value of $t$ tests $\geq 0.01$ and $<0.5 ;{ }^{* *} P$ value of $t$ tests $<0.01$.

The differences in mean values for theechocardiographic parameters of major diastolic function, according to the presence of hypovitaminosis D, can be seen in Table 4 . All parameters classified as markers of major diastolic dysfunction (non-indexed LAD and LAV, E' / $\mathrm{A}^{\prime}$ and E-wave deceleration time) showed an association with the presence of hypovitaminosis $\mathrm{D}$. The $\mathrm{E} / \mathrm{A}$ ration, classified as a marker of minor diastolic dysfunction, was also associated with the presence of hypovitaminosis D (Table 5).

Associations of OSA risk with parameter markers of major diastolic dysfunction and remodeling can be seen 
Table 5 - Differences in means of echocardiographic parameters as markers of minor diastolic dysfunction according with the presence of Hypovitaminosis D

\begin{tabular}{lcc}
\hline $\begin{array}{l}\text { Parameters measured } \\
\text { by echo-Doppler }\end{array}$ & $\begin{array}{c}\text { Hypovitaminosis } \\
\text { D }\end{array}$ & L \\
\hline \multirow{2}{*}{ E (cm/s) } & Yes & $64,85 \pm 1,1$ \\
& No & $66,86 \pm 0,9$ \\
A $(\mathrm{cm} / \mathrm{s})$ & Yes & $70,32 \pm 1,36$ \\
& No & $67,6 \pm 1,07$ \\
E/A & Yes & $0,98 \pm 0,02^{* * *}$ \\
\hline \multirow{2}{*}{$* * *$ value of $t$ tests $<0.01$} & No & $1,07 \pm 0,02$ \\
\hline
\end{tabular}

in Table 6. Parameters of cardiac (ventricular) geometry (IVS, RWT, LVPWT and LVEDD) were associated with the presence of hypovitaminosis $\mathrm{D}$.

There was no difference in mean values of echocardiographic parameters, which assessed the systolic function from the presence of hypovitaminosis $\mathrm{D}$. Both ejection fraction and analysis by Tissue Doppler Imaging (S wave) did not reveal any abnormalities that could represent systolic dysfunction (Table 7).

\section{Discussion}

This study examined the risk of diastolic dysfunction (DD) in a population with hypovitaminosis D, using a marker to assess the vitamin D nutritional status and tissue Doppler echocardiography to evaluate parameters of systolic and diastolic function.

In our study, we investigated whether the patients who had hypovitaminosis D would be associated with diastolic dysfunction, and we observed that DD was more prevalent among these individuals.

We noted that both indexed (i) LV diameter and volume (a diastolic dysfunction marker) were strongly associated with the presence of diastolic dysfunction, and identified by echocardiography. In accordance with our study, Rahman et al., ${ }^{17}$ have concluded that Vitamin D reduction $(<20 \mathrm{ng} / \mathrm{ml})$ seems to be correlated with worsened systolic function in terms of end-systolic volume and end-systolic dimension. ${ }^{17}$
Table 6 - Difference in means of echocardiographic parameters as indicators of major diastolic dysfunction that indicate remodeling according with the presence of Hypovitaminosis D

\begin{tabular}{|c|c|c|c|c|}
\hline $\begin{array}{l}\text { Parameters } \\
\text { measured } \\
\text { by echo- }\end{array}$ & & Hyp & minosis D & \\
\hline & Yes & & $163,05 \pm 2,71$ & \\
\hline 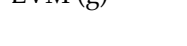 & No & & $156,25 \pm 2,35$ & \\
\hline & Yes & & $91,05 \pm 1,43$ & \\
\hline ש & No & & $91,14 \pm 1,24$ & \\
\hline & Yes & & $110,49 \pm 1,48$ & \\
\hline & No & & $109,79 \pm 1,27$ & \\
\hline & Yes & & $75,46 \pm 1,15$ & \\
\hline & No & & $74,98 \pm 0,97$ & \\
\hline$c U(-1)$ & Yes & & $61,89 \pm 0,81$ & ** \\
\hline & No & & $64,27 \pm 0,69$ & \\
\hline & Yes & * & $8,08 \pm 0,08$ & ** \\
\hline & No & & $7,86 \pm 0,07$ & \\
\hline & Yes & & $0,33 \pm 0$ & * \\
\hline$K V 1$ & No & & $0,32 \pm 0$ & \\
\hline & Yes & * & $7,95 \pm 0,07$ & ** \\
\hline & No & & $7,7 \pm 0,06$ & \\
\hline & Yes & $* * *$ & $61,89 \pm 0,81$ & ** \\
\hline LVLD & No & & $64,27 \pm 0,69$ & \\
\hline
\end{tabular}

${ }^{*} P$ value of $t$ tests $\geq 0.05$ and $<0.1 ;{ }^{* *} P$ value of $t$ tests $\geq 0.01$ and $<0.5 ;{ }^{* * *} P$ value of $t$ tests $<0.01$.

Table 7 - Differences in means of echocardiographic parameters as markers of systolic dysfunction according with the presence of Hypovitaminosis D

\begin{tabular}{lcc}
\hline $\begin{array}{l}\text { Parameters measured } \\
\text { by echo-Doppler }\end{array}$ & $\begin{array}{c}\text { Hypovitaminosis } \\
\text { D }\end{array}$ \\
\hline \multirow{2}{*}{$\mathrm{SEF}(\%)$} & Yes & $61,56 \pm 0,37$ \\
& No & $61,55 \pm 0,32$ \\
$\mathrm{~S}(\mathrm{~cm} / \mathrm{s})$ & Yes & $8,36 \pm 0,12$ \\
& No & $8,36 \pm 0,1$ \\
\hline
\end{tabular}


There is little research on hypovitaminosis under this condition in primary care and, especially, when it is correlated with cardiovascular changes. Our study was pioneer in dealing with vitamin $\mathrm{D}$ deficiency in primary care. Most studies associate cardiovascular diseases with serum levels of vitamin D. A study indicated that a 25-hydroxyvitamin $\mathrm{D}(25[\mathrm{OH}] \mathrm{D})$ may be an important marker or modulator of the functional capacity in heart failure patients. ${ }^{18}$ Pekkanen et al., ${ }^{19}$ investigated whether the $(25(\mathrm{OH}) \mathrm{D} 3)$ concentration would be associated with high cardiovascular risk factors and cardiac structure and function in patients with coronary heart disease. Among other results, they found that low vitamin D is associated with several cardiovascular risk factors and structural cardiac changes, heart failure with preserved ejection fraction and heart failure with reduced ejection fraction. ${ }^{19}$ In another study, Polat et al., ${ }^{20}$ observed a significant negative correlation between 25OHD3 concentrations and LV diastolic and end-systolic dimensions. ${ }^{20}$

In a population of patients $(n=281)$, who were referred to coronary angiography for stable angina pectoris, Akin et al., ${ }^{21}$ verified that the LV mass index, the LA diameter, the isovolumic relaxation time and the $\mathrm{E}^{\prime} / \mathrm{E}$ ratio were significantly higher in patients with lower levels of 25 $(\mathrm{OH}) \mathrm{D} 3$ and the authors concluded that serum levels of $25(\mathrm{OH}) \mathrm{D}$ are significantly associated with LV diastolic dysfunction and LV mass index. ${ }^{21}$

There is growing evidence to support the important role of vitamin D and Fibroblast growth factor 23 (fgf23) hormone in cardiac remodeling. $\mathrm{KyB}$ et al. investigated this association and found significant interactions between $25(0 \mathrm{H}) \mathrm{D}, 1.25(0 \mathrm{H})$ and FGF23 in cardiac remodeling and, as in other studies already mentioned, the authors found increased LV mass and cavity dilation associated with low $25(\mathrm{OH}) \mathrm{D}$ concentrations and increased FGF23 levels. Both hormones are crucial for an understanding of the role of cardiac remodeling and may have major therapeutic implications. In addition, LAV increase is described through several pathophysiological mechanisms, which are likewise triggered by reduced LV diastolic and systolic function and SRAA activation. ${ }^{22}$

A study carried out by Jorge et al. investigated whether VitD deficiency among patients with suspected heart failure with normal ejection fraction had any correlations with systolic and diastolic function markers. Among other results, they found that HFNEF patients had lower serum VitD levels and almost half were VitD deficient. They also noted a negative correlation between $\mathrm{VitD}$ and the $\mathrm{E} / \mathrm{E}^{\prime}$ ratio, a LV filling pressure marker. ${ }^{23}$
Recently, Aghajani et al., ${ }^{24}$ evaluated the longitudinal left ventricular function in patients with coronary artery ectasia (CAE) and vitamin D deficiency by echocardiography. The results showed that LV systolic and diastolic function in patients with CAE and Vitamin D deficiency were impaired. ${ }^{24}$ Another study on supplementation showed that D-deficient prediabetic African American males who were treated with highdose vitamin D2 were found to have attenuated increases in left atrial volume compared with controls over 12-month follow-up. ${ }^{25}$

Our findings are in line with what is described in the literature. We found associations with the parameters that represent diastolic dysfunction, since their stages of incipient dysfunction (assessed on conventional Doppler), until more advanced stages, which include increased filling pressures, using tissue Doppler imaging and parameters that reveal structural changes, notably $\mathrm{LAV}$, which reflects the duration and severity of diastolic dysfunction, obtained from determination of LAV. ${ }^{26}$

Based on the results found in our study, the monitoring of Vitamin D levels in the population served by primary health care programs, such as the Médico de Família program, would be helpful in selecting patients at risk of developing cardiovascular changes due to diastolic dysfunction and who should be referred for early echocardiographic evaluation.

\section{Conclusion}

The study of the association between hypovitaminosis $\mathrm{D}$ and the development of structural and functional cardiac anomalies can contribute with the discussion about the adoption of a new criterion in the selection of individuals at risk of developing clinical heart failure in primary care. Echocardiography allows for early detection of the subclinical condition of cardiac involvement, with prognostic and treatment implications for patients tested for vitamin D status, when the results suggest increased clinical suspicion for diastolic dysfunction.

\section{Clinical Application}

This study shows that Vitamin D nutritional status assessment is justified as a diagnostic method for detecting changes in cardiac structure and function. Even in asymptomatic individuals or under the influence of risk factors, it is possible to detect changes in cardiac remodeling and function, differentiate stage $\mathrm{A} \mathrm{HF}$ from 
stage B HF, which can significantly change prognosis and treatment.

Thus, vitamin D status measurement is a useful tool for classifying patients at increased risk of diastolic dysfunction in primary healthcare. Nutritional assessment of Vitamin D status allows for risk stratification of patients from the very beginning of healthcare assistance. The echocardiographic evaluation performed after patient screening and selection can provide an early and accurate diagnosis in the initial stages of heart failure (A and B).

\section{Limitations}

This was a cross-sectional observational study, which did not enable the establishment of cause and effect relationships, because coexistence in clinical settings can hinder this evaluation, which may be concluded through longitudinal analysis.

The study sought to assess a representative sample of the general population. However, we could not completely exclude the selection bias, due to the higher demand for health services by female patients.

Echocardiographic tests were performed using two portable equipment from distinct manufacturers, which did not permit storage on backup devices, so that we would be able to calculate the intra- and inter-examiner coefficient of variation.

The equipment did not have advanced techniques for cardiac deformation imaging, and the evaluation is restricted to the tissue technique, which may underestimate the involvement of systolic function assessment in the sample.

\section{References}

1. Feigenbaum H, Amstrong WF, Ryan T. Ecocardiografia. 6a ed. Rio de Janeiro: Guanabara Koogan; 2007.

2. Kircher B, Abbott JA, Pau S, Gould RG, Himelman RB, Higgins CB, et al. Left atrial volume determination by biplane two-dimensional echocardiography: validation by cine computed tomography. Am Heart J. 1991;121(3 t 1):864-71.

3. $\mathrm{OH}$ JK, Seward JB, Tajik AJ. The echo manual. 3rd ed. Philadelphia: Lippincott Williams \& Wikilkins; 2006.

4. Mesquita ET, Jorge AJL. ICFEN - Insuficiência cardíaca com fração de ejeção normal. São Paulo: Ed. Atheneu; 2009.

5. Montera VSP, Mesquita ET. O The role of vitamin D in heart failure. Rev Bras Cardiol. 2010;23(2):124-30.

6. ZIttermann, A. Vitamin D status, supplementation and cardiovascular disease. Anticancer Res. 2018;38(2):1179-86.

\section{Author contributions}

Conception and design of the research: Macedo EA. Analysis and interpretation of the data: Jorge AJL, Leite AR. Statistical analysis: Rosa MLG. Writing of the manuscript: Santos LHS. Critical revision of the manuscript for intellectual content: Vieira JS.

\section{Potential Conflicts of Interest}

The authors have no relevant conflict of interests to disclose.

\section{Sources of funding}

The study was financed by the authors. Laboratory tests were donated by Sergio Franco Laboratories and Abbott Laboratory (BNP). Echocardiography and electrocardiography tests were conducted by researchers of the DIGITALIS Study.

\section{Study Association}

This manuscript is part of the Master's dissertation of Erica de Abreu Macedo from Universidade Federal Fluminense.

\section{Ethics approval and consent to participate}

This study was approved by the Ethics Committee of the Universidade Federal Fluminense under the protocol number 0077.0.258.000-10. All the procedures in this study were in accordance with the 1975 Helsinki Declaration, updated in 2013. Informed consent was obtained from all participants included in the study.

7. Jorge AJL, Cordeiro JR, Rosa MLG, Bianchi, DBC. Vitamin D deficiency and cardiovascular diseases. Int J Cardiovasc. Sci. 2018;31(4):422-32.

8. Witham D, Crighton LJ, Gillespie ND, Struthers AD, McMurdo ME. The effects of vitamin D supplementation on physical function and quality of life in older patients with heart failure: a randomized controlled trial. Circ Heart Fail. 2010;3(2):195-201.

9. Rendina D, De Fillippo G, Strazzulo P. Should vitamin D status be assessed in patients with congestive heart failure? Nutr Metab Cardiovasc Dis. 2010;20(9):627-32.

10. Pilz S, Tomaschitz A, Drechsler C, Dekker JM, März W. Vitamin D deficiency and myocardial diseases. Mol Nutr Food Res. 2010;54(8):1103-13.

11. Jorge AJL, Rosa ML, Fernandes LCM, Freire MC, Rodrigues RC, Correia DMS, et al. Heart Failure Prevalence Study among Patients Enrolled in 
the Family Health Program, Niterói. The DIGITALIS Study: design and method. Rev Bras Cardiol. 2011;24(5):320-5.

12. Lang RM, Bierig M, Devereux RB, Flachskampf FA, Foster E, Pellikka PA, et al. Recommendations for chamber quantification. Eur J Echocardiogr. 2006;7(2):79-108.

13. Otto CM. Fundamentos de ecocardiografia clínica. 4a ed. Laianza AC, tradutor. Rio de Janeiro: Elsevier; 2010.

14. Sousa AC. Left atrial volume as an index of diastolic function. Arq Bras Cardiol. 2006;87(3):e27-33.

15. Ferreira CES, Maeda SS, Batista MC, Lazaretti-Castro M, Vasconcellos LS, Madeira M, et al. Consensus - reference ranges of vitamin D [25(OH)D from the Brazilian medical societies. Brazilian Society of Clinical Pathology / Laboratory Medicine (SBPC/ML) and Brazilian Society of Endocrinology and Metabolism (SBEM). J Bras Patol Med Lab. 2017;53(6);377-81.

16. Nagueh SF, Appleton CP, Gillebert TC, Marino PN, Oh JK, Smiseth OA, et al. Recommendations for the evaluation of left ventricular diastolic function by echocardiography. J Am Soc Echocardiogr. 2009;22(2):107-33

17. Rahman MAA, Galal H, Omar AMS. Correlation between serum vitamin D level and cardiac function: Echocardiographic assessment. Egyptian Heart J. 2015;67(4):299-305.

18. Boxer RS, Kenny AM, Cheruvu VK, Vest M, Fiutem JJ, Piña II. Serum 25-hydroxyvitamin D concentration is associated with functional capacity in older adults with heart failure. Am Heart J. 2010;160(5):893-9.

19. Pekkanen MP, Ukkola O, Hedberg P, Piira OP, Lepojärvi S, Lumme J, et al. Serum 25-hydroxyvitamin $\mathrm{D}$ is associated with major cardiovascular risk factors and cardiac structure and function in patients with coronary artery disease. Nutr Metab Cardiovasc Dis. 2015;25(5):471-8.

20. Polat V, Bozcali E, Uygun T, Opan S, Karakaya O. Low vitamin D status associated with dilated cardiomyopathy. Int J Clin Exp Med. 2015;8(1):1356-62.

21. AKin F, Ayca B, Köse N, Celik O, Yilmaz Y, Akin MN, et al. Serum vitamin $\mathrm{D}$ and $\mathrm{C}$-reactive protein levels are independently associated with diastolic dysfunction. J Investig Med. 2014;62(1):43-8.

22. Ky B, Shults J, Keane MG, Sutton MS, Wolf M, Feldman HI, et al. FGF23 modifies the relationship between vitamin $\mathrm{D}$ and cardiac remodeling. Circ Heart Fail. 2013;6(4):817-24.

23. Jorge AJ, Rosa MLG, Freire MC, Correia DMS, Fernandes LCM, Ribeiro $\mathrm{ML}$, et al. Deficiência de vitamina D em pacientes com suspeita de insuficiência cardíaca e fração de ejeção normal. Rev Bras Cardiol. 2013;26(4):253-8.

24. Aghajani H, Faal M, Hosseinsabet A. Evaluation of longitudinal left ventricular function in patients with coronary artery ectasia and vitamin $\mathrm{D}$ deficiency by $2 \mathrm{D}$ speckle tracking echocardiography. Echocardiography. 2017;34(3):397-406.

25. Chacko S J, Pauwaa S, Barengolts E, Ciubotaru I, Kansal MM. Vitamin $\mathrm{D}$ attenuates left atrial volume changes in African American males with obesity and prediabetes. Echocardiography. 2016;33(5):681-5.

26. Mancuso JN, Moises VA, Almeida DR, Poyars D, Storti LJ, Oliveira WA, et al. Left Atrial Volume Determinants in Patients with Non-Ischemic Dilated Cardiomyopathy. Arq Bras Cardiol. 2015;105(1):65-70. 